\title{
An Integrative Framework for the Analysis of Multiple and Multimodal Representations for Meaning-Making in Science Education
}

\author{
KOK-SING TANG,${ }^{1}$ CESAR DELGADO,${ }^{2}$ ELIZABETH BIRR MOJE ${ }^{3}$ \\ ${ }^{1}$ National Institute of Education, Nanyang Technological University, Singapore 637616; \\ ${ }^{2}$ College of Education, University of Texas at Austin, Austin, TX 78712, USA; ${ }^{3}$ School of \\ Education, University of Michigan, Ann Arbor, MI 48109, USA
}

Received 30 August 2012; accepted 18 December 2013

DOI 10.1002/sce.21099

Published online 30 January 2014 in Wiley Online Library (wileyonlinelibrary.com).

\begin{abstract}
This paper presents an integrative framework for analyzing science meaningmaking with representations. It integrates the research on multiple representations and multimodal representations by identifying and leveraging the differences in their units of analysis in two dimensions: timescale and compositional grain size. Timescale considers the duration of time a learner typically spends on one or more representations. Compositional grain size refers to the elements of interest within a representation, ranging from components such as visual elements, words, or symbols, to a representation as a whole. Research on multiple representations focuses on the practice of re-representing science concepts through different representations and is typically of long timescale and large grain size. Research on multimodal representations tends to consider how learners integrate the components of a representation to produce meaning; it is usually of finer grain size and shorter timescale. In the integrative framework, each type of analysis on multiple and multimodal representations plays a mutually complementary role in illuminating students' learning with representations. The framework is illustrated through the analysis of instructional episodes of middle school students using representations to learn nanoscience concepts over the course of a lesson unit. Finally, recommendations for new research directions stemming from this framework are presented. (c) 2014 Wiley Periodicals, Inc. Sci Ed 98:305-326, 2014
\end{abstract}

Correspondence to: Kok-Sing Tang; e-mail: koksing.tang@nie.edu.sg

This research is supported by the National Center for Learning and Teaching in Nanoscale Science and Engineering (NCLT) under National Science Foundation Grant \#0426328. 


\section{INTRODUCTION}

Representations are artifacts that symbolize an idea or concept in science (e.g., force, energy, chemical bonding) and can take the form of analogies, verbal explanations, written texts, diagrams, graphs, and simulations. As such, they are an integral part of the language of science. The National Science Foundation (NSF), recognizing the need for a greater understanding of representation, funded two "cross-border" conferences that brought together researchers from the literacy, cognitive science, and science education communities. These conferences determined that further syntheses and frameworks are needed to explain how representation promotes science literacy (Hand et al., 2003). Specifically, greater understanding is needed on two areas of research on representation: multiple representations and multimodal representations (Yore \& Treagust, 2006).

The term "multiple representations" denotes the practice of representing to students the same concept through different representational forms (Prain \& Waldrip, 2006). Research on multiple representations has focused on how the use of more than one representation affects student understanding (e.g., Ainsworth, 2006; Gilbert \& Treagust, 2009; Kozma, 2003; Prain, Tytler, \& Peterson; 2009). The term "multimodal representations" refers to the fact that learning with one or more representations usually integrates components of various modalities such as language, depiction, and symbols (Prain \& Waldrip, 2006). This area of research on multimodality examines how students build scientific understanding through the simultaneous use of various modalities within and across representations (e.g., Airey \& Linder, 2009; Kress, Jewitt, Ogborn, \& Tsatsarelis, 2001; Lemke, 1998).

Research on multiple representations and multimodality are well established in science education research. However, there have been few attempts to integrate these disparate areas of research (Yore \& Hand, 2010). We posit that the central difficulty in linking the two research areas lies in their different units of analysis, focusing on the number of representations used in a teaching or learning context. The different units of analysis result in differences along two dimensions: timescale and compositional grain size. The purpose of this paper is to present a framework that leverages these two dimensions to connect the two areas of research, as well as to suggest additional directions for research. In doing so, this paper advances the vision of a multirepresentational framework first put forth by Yore and Treagust (2006).

In the next sections, we define the two dimensions of timescale and compositional grain size and use them to organize prior research on representation. We then present our framework and show how it integrates multiple representations and multimodal foci through an analytical case study. Finally, the implications of this framework for future research on representation are discussed.

\section{THEORETICAL BACKGROUND}

\section{Timescale and Compositional Grain Size as Dimensions of the Unit of Analysis}

As mentioned above, research on multiple representations and multimodality typically use different units of analysis. In studying how several representations can interact to support student learning, research on multiple representations usually considers a longer timescale and uses a larger compositional grain size. On the other hand, research on multimodality examines how learners make sense of a representation consisting 
of multiple modalities and is characterized by shorter timescales and finer compositional grain size.

Timescale. According to Lemke (2000), there are characteristic timescales of reoccurring processes observed in classroom events, ranging from a single utterance in seconds, to an exchange of teacher-student or student-student dialogue in minutes, a full lesson in an hour, a lesson unit in days, and finally a curriculum and program in months and years. To understand classroom events, one must observe how the processes at a shorter timescale build up to the processes at a longer timescale and conversely how the longer timescale processes constrain and enable the kind of processes that can occur at a shorter timescale (Lemke, 2000). Making sense of the elements within a representation, which is the focus of multimodality, usually involves shorter temporal scales of seconds or a few minutes. Using and transforming several tables, diagrams, or graphs from one form to another, which is the focus of multiple representations, usually involves longer timescale of at least one lesson period. The dimension of timescale is continuous, but it is conceptually useful to divide it into two levels. For the purpose of studying representation, we define a short timescale as less than a lesson period.

Compositional Grain Size. Compositional grain size refers to the elements that make up a representation (Tang \& Moje, 2010). For a written text, compositional grain sizes could range from letters as the smallest components, to words, phrases, clauses, sentences, paragraphs, pages, and sections. For a visual diagram, the components could range from lines or shapes to the entire diagram. For example, the finest grained components of a molecular depiction of air exerting pressure on its container are the lines (representing the container), dots (representing molecules), and arrows (representing motion) drawn in the diagram. The intermediate components of a diagram are clusters, or local groupings of spatially proximate items, which define a specific subregion of the diagram as a whole (see Baldry \& Thibault, 2006). Finally, the largest compositional grain size can be one or more diagrams in their entirety. While many compositional grain sizes can be defined, we define just two levels, with fine grain size defined as consisting of less than an entire representation.

\section{Relationship Between Timescale and Compositional Grain Size}

Archetypically, multiple representation studies feature longer timescale and larger compositional grain size, whereas multimodality studies are characterized by shorter timescale and finer compositional grain size. However, the two dimensions of timescale and grain size are independent, and thus define four possible combinations. We depict these in a two-by-two space with timescale on the horizontal dimension and grain size on the vertical dimension. We next describe representative studies that fall in each of the four quadrants. Figure 1 shows this two-by-two space, populated by research studies in each of the quadrants.

Analysis With Long Timescale and Large Grain Size. A good example of an analysis of multiple representations with a long timescale and large grain size (the top left quadrant of Figure 1) is the study by Hubber, Tytler, and Haslam (2010) in the context of forces. They focused not only on the representations used in class but also on "re-representation": How representations were transformed from one representation to the next (e.g., drawing 


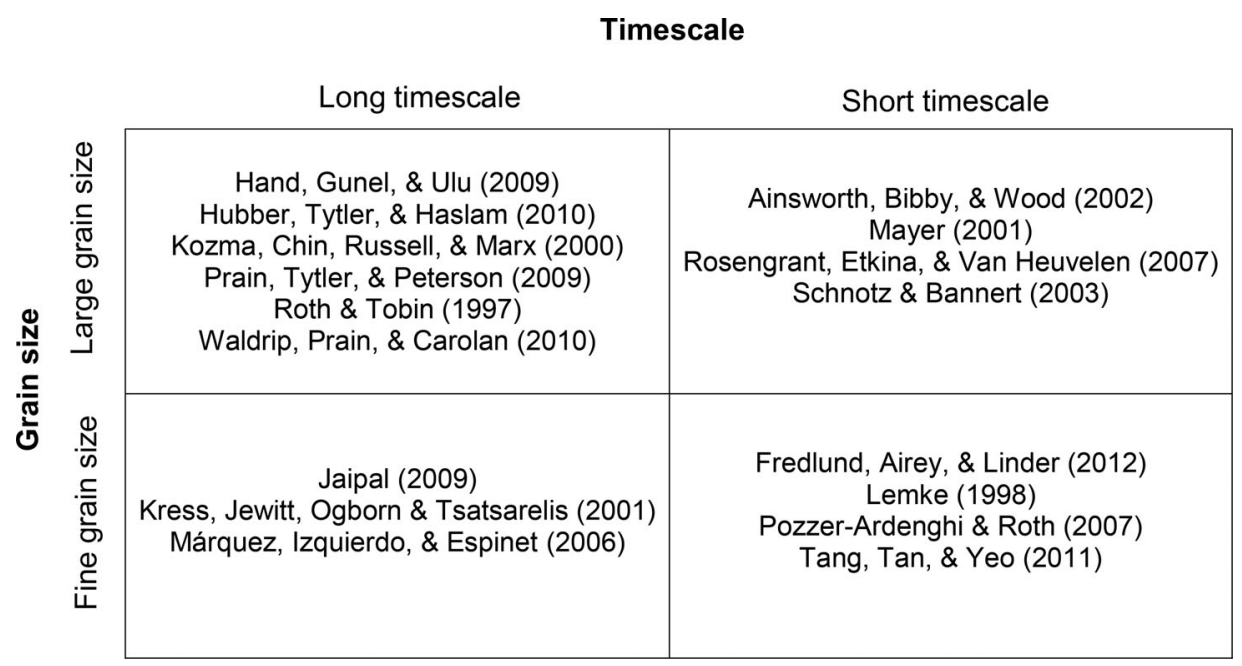

Figure 1. Map of the problem space: timescale and grain size. Studies are classified according to their temporal and compositional characteristics.

to table to graph). Re-representation can occur within the same modality (e.g., from one written text to another) or across multiple modalities (e.g., from text to graphs). Working at a timescale over 12 lessons, they worked with the teachers to develop what they called "a representational approach" to the teaching of forces. The pedagogical principles in this approach include (i) introducing multiple representations of the concept, (ii) encouraging students to generate their own representations, and (iii) linking representations to experiential activity, discussion, cognition, and communication. In one of their analyses, they studied how the dynamic transformations in the students' representations corresponded with the teaching and learning sequences. The sequence of re-representations made by the students included everyday words associated with forces, gestures miming the actions, drawings of their actions, drawings of the effects on modeling clay, and force diagrams with arrows. The unit of analysis selected by Hubber and colleagues comprised multiple representations used in a lesson, because they were interested in re-representation. This focus required a longer timescale to study the dynamic generation and negotiation of representations and their transformations. The large grain size corresponds to a view of a representation as a self-contained artifact designed with some specific science concept in mind. Additional studies of this type are listed in Figure 1.

Analysis With Short Timescale and Fine Grain Size. An example of an analysis with a finer grain size and shorter timescale (at bottom right quadrant of Figure 1) is Lemke's (1998) multimodal analysis of printed scientific texts. In one of his analytical examples, Lemke first decomposed a figure into various visual components such as shaded circles, arrow vectors, parallel lines, and dashed lines. He then considered how the qualities of each component relate to those of other components in the construction of scientific meanings. Lemke did not observe readers interacting with the representation but presumably this interaction would occur over a period of a few minutes. In another multimodal study, Tang, Tan, and Yeo (2011) analyzed the critical connections among multimodal elements that constitute the concept of work-energy. They analyzed in detail three episodes of the discussion among a group of students, each lasting a few minutes. They 
found that students constructed knowledge through the integration of four modalities: language, diagrams, mathematical symbolism, and gestures. Each modality had different roles and functions. Both studies feature a unit of analysis of a single representation, observed over a shorter timescale, and focusing on the fine-grained compositional elements of various modalities that constitute the representation. Their ultimate aim was to analyze how those elements related with one another in the overall construction of scientific concepts.

These and other multimodal studies are based on Halliday's (1978) theory of social semiotics. Social semiotics is the study of sign systems and their use in meaning-making as a function of a social process. An important notion in social semiotics is semiotic affordances, which examines the possibility of different kinds of meaning that are made available through the use of different modalities (Kress et al., 2001). For instance, a linguistic modality in general allows or affords a person to make categorical types of meaning (e.g., of what kind), whereas a visual modality affords a person to make quantitative types of meaning (e.g., by how much). Multimodality and semiotic affordances are useful notions because they provide a metalanguage and analytical tools to examine the fine-grained components of a representation and to understand how the components come together to form meanings (see Figure 1 for additional studies with short timescale and fine grain size).

Analysis With Short Timescale and Large Grain Size. Studies in this category (top right in Figure 1) analyze the design features and parameters of different representations used to promote conceptual learning. Ainsworth (2006) studied the different functions of multiple representations and generated a taxonomy of functions that included constraining interpretations, complementing each other, or constructing deeper meaning. Schnotz and Bannert (2003) studied how learners use text and pictures to construct their understanding. Drawing from Chandler and Sweller's (1996) cognitive load theory and Mayer's (2001) dual sensory processing theory, they proposed an integrated model of text and picture comprehension. Based on this model, they designed a randomized-trial experiment to compare learning with text alone and with text and diagrams of two different types. The unit of analysis in both studies is one or more entire representations. The timescale associated with these studies is short, at the level of a task (ranging from 1 to 5 minutes). The compositional grain size is large, composed of representations as a whole. Other studies with short timescale and large grain size are listed in Figure 1.

Analysis With Long Timescale and Fine Grain Size. Studies of this type (bottom left quadrant in Figure 1) use a fine-grained analytical approach, but investigate a phenomenon that occurs at a longer timescale. Márquez and colleagues (2006) were interested in the communicative roles of different modalities used by a secondary science teacher. They studied a lesson unit on the water cycle, composed of five 55-minutes lessons. They used Halliday's (1994) linguistic framework and Kress and van Leeuwen's (2006) visual framework to carry out a fine-grained decomposition of the verbal discourse and pictorial representations, respectively. For instance, in analyzing a visual representation of the water cycle, Márquez et al. examined the arrows within this representation and identified three different meanings of these arrows within the context of the visual representation. They then used categorization and statistical analyses to investigate the functions of speech, gesture, and diagram in relation to the thematic construction of water cycle. Although various representations were involved, the interactions of the components of each representation were considered, making this a fine-grained analysis with a long timescale. Additional studies with long timescale and fine grain size are shown in Figure 1.

Science Education, Vol. 98, No. 2, pp. 305-326 (2014) 


\section{AN INTEGRATIVE FRAMEWORK FOR THE ANALYSIS OF MULTIPLE AND MULTIMODAL REPRESENTATIONS}

From the above analysis of the literature in representation studies, one can see the disparate foci based on the two dimensions of timescale and compositional grain size. We developed our framework with the aim of incorporating a wider range of timescale and grain size in the analysis of representation, in effect integrating across multiple representations and multimodal approaches.

We begin developing our framework from the definition of a representation as a designed artifact. Drawing from the literature on multiple representations, we incorporate the theoretical notion of re-representation (Hubber et al., 2010) as the transformation of representations from one artifact to another across a continuous chain of human activities. This expands our scope from representation as an artifact to representation as a process of meaning-making that makes use of representations as mediating tools. This also broadens the timescale of analysis from an activity involving one designed artifact (usually in minutes) to a sequence of representational activities in a lesson or lesson unit. We then draw on the literature on multimodality to incorporate the notion of semiotic affordances, which examines the possibilities and constraints of a representation's meaning-making potential. A focus on semiotic affordances expands the range of our compositional grain size from a representation as a unitary whole to include the smaller semiotic elements that constitute the artifact and its meaning potential. The focus on semiotic affordances allows us to examine how the short timescale events build up to the processes at a longer timescale, whereas the incorporation of re-representation affords understanding how the longer timescale events constrain and support shorter timescale events (Lemke, 2000).

Our integrative framework is shown visually in Figure 2. The notion of re-representations (at top of Figure 2) considers the sequences of representations that might be used in a lesson unit, focusing on the process of transforming one representation to the next and also how one representation relates to the others (e.g., constraining interpretations; Ainsworth, 2006). In this example, the naked-eye examination of a sample is followed by the use of a microscope, with students producing drawings of each (the first two objects from left to right). Students next produce a diagram (third object from left) that captures important qualitative aspects of the phenomenon, then produce measurements that they organize into a table, then a graph displaying the mathematical equation that models the phenomenon (the last two objects). This level of analysis involves a longer timescale and larger compositional grain size. On the other hand, the semiotic affordances analysis (at bottom of Figure 2) takes a fine-grained look at one representation at a time. It examines how the composition and integration of the various elements (lines, curves, arrows, boxes, words, symbols, numbers) afford a person who is using it to construct meaning related to the phenomenon. This process usually occurs at a shorter timescale. The relationship between re-representation and semiotic affordances (the top and bottom part of Figure 2) is iterative and cyclical, each analysis informing the other. In the next section, we demonstrate the use of this framework through a case study.

\section{METHODS}

\section{Research Context and Data Sources}

We use a case study to illustrate our integrative framework, which we originally developed to understand how student make meanings with representations. Our case study is located in a free 2-week summer program in the U.S. Midwest, attended by 40 students from 


\section{A sequence of re-representations}

constraining/complementing/constructing function

Re-representation from multiple representations

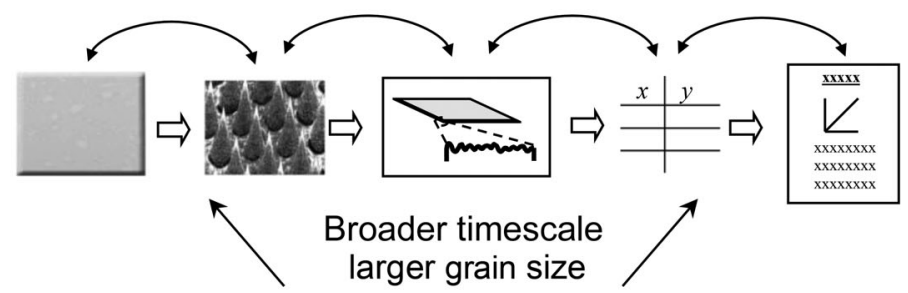

\section{Semiotic affordances from multimodal representations}

A representation artifact
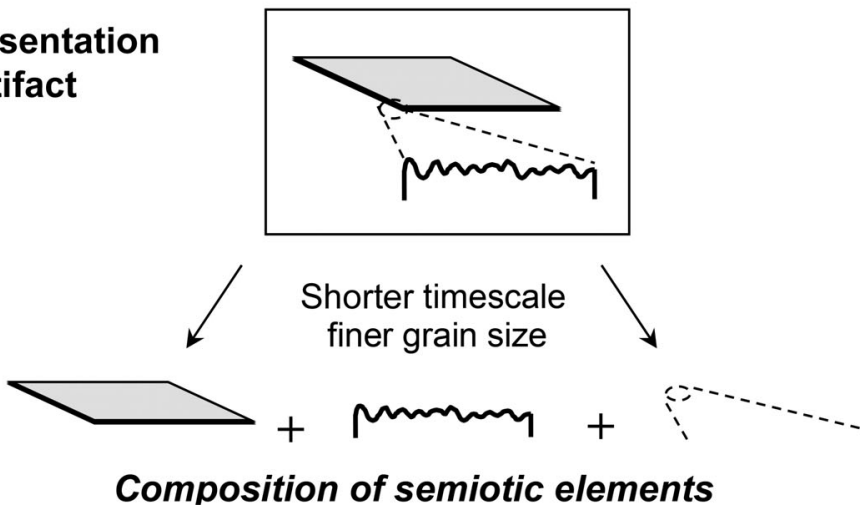

Figure 2. Our integrative framework for the analysis of multiple and multimodal representations.

two local middle schools who volunteered to participate. The summer program was a collaboration between an NSF-funded research center, the school district, and an outreach program affiliated with a university hospital. We researched a curriculum strand designed to teach the concepts of size and scale in six lessons.

The curriculum was designed following a project-based pedagogical approach (Krajcik \& Blumenfeld, 2006) where the students learn by carrying out a series of empirical investigations to address a real-world problem. The project was contextualized with the real-life case of a middle school student who died of an antibiotic-resistant bacterial infection contracted at his school. Students worked in groups to investigate the problem, create artifacts, and report their suggested solutions. Our use of representations was guided by studies on multiple representations. Representations used in the lesson activities included physical, three-dimensional scale models of nanoscale objects such as DNA and viruses along with two- and one-dimensional representations of larger objects (e.g., cells) at the same scale, videos of commercial products designed to reduce bacterial infections, and computer visualizations. Consistent with Hubber et al.'s (2010) re-representational approach, students generated their own representations linked to various activities throughout the lessons, such as sketches of objects viewed under the microscope and posters presenting their ideas.

The primary data source was videotaped observations, recorded by one camera focused on the lead teacher and another focused on the interactions of several groups of students. In this paper, we report our observations primarily from a group of students consisting of Mary, Luke, and Dave (all names are pseudonyms to protect privacy), with the other groups providing confirming and disconfirming evidences to our assertions. Additional data sources were observation fieldnotes, instructional materials, and students' completed artifacts. The first author took the role of a participant-observer in collecting the data. 


\section{TABLE 1}

An Example of Segmentation and Corresponding Tags from the First Lesson

\begin{tabular}{|c|c|c|c|c|}
\hline $\begin{array}{l}\text { Video } \\
\text { Time }\end{array}$ & $\begin{array}{c}\text { Description of } \\
\text { Teaching/Learning } \\
\text { Activities }\end{array}$ & $\begin{array}{l}\text { Participation } \\
\text { Structure }\end{array}$ & $\begin{array}{l}\text { Thematic } \\
\text { Content }\end{array}$ & $\begin{array}{l}\text { Representations } \\
\text { Used }\end{array}$ \\
\hline 1:33:34 & $\begin{array}{l}\text { Teacher introduces } \\
\text { sandpaper } \\
\text { experiment }\end{array}$ & $\begin{array}{l}\text { Monologue }+ \\
\text { lab demo }\end{array}$ & $\begin{array}{l}\text { Modeling } \\
\text { bacteria } \\
\text { buildup }\end{array}$ & $\begin{array}{l}\text { Sandpapers + salt } \\
\quad \text { (apparatus) }\end{array}$ \\
\hline $1: 35: 45$ & $\begin{array}{l}\text { Teacher instructs } \\
\text { students on how } \\
\text { to report on } \\
\text { worksheet }\end{array}$ & Monologue & & Table on whiteboard \\
\hline $1: 36: 16$ & $\begin{array}{l}\text { Individual students } \\
\text { carry out } \\
\text { experiment and } \\
\text { record on their } \\
\text { worksheet }\end{array}$ & Seatwork & & $\begin{array}{l}\text { Sandpapers + salt } \\
\text { (apparatus), table } \\
\text { on worksheet }\end{array}$ \\
\hline $1: 44: 26$ & $\begin{array}{l}\text { Teacher draws and } \\
\text { explains what a } \\
\text { side view is }\end{array}$ & Class dialogue & $\begin{array}{l}\text { Surface } \\
\text { feature }\end{array}$ & $\begin{array}{l}\text { Sandpaper } \\
\text { (apparatus), } \\
\text { drawing on } \\
\text { whiteboard }\end{array}$ \\
\hline $1: 45: 46$ & $\begin{array}{l}\text { Groups draw a } \\
\text { poster to explain } \\
\text { the sandpaper } \\
\text { experiment }\end{array}$ & Group work & $\begin{array}{c}\text { Explaining } \\
\text { bacteria } \\
\text { buildup }\end{array}$ & $\begin{array}{l}\text { Sandpapers + salt } \\
\text { (apparatus), } \\
\text { writing/drawings } \\
\text { on poster paper }\end{array}$ \\
\hline $2: 03: 47$ & $\begin{array}{l}\text { Teacher gives } \\
\text { instruction for } \\
\text { presentation }\end{array}$ & Monologue & & Nil \\
\hline $2: 04: 25$ & First group presents & $\begin{array}{l}\text { Group } \\
\quad \text { presentation }\end{array}$ & & $\begin{array}{l}\text { Writing/drawings on } \\
\text { poster paper }\end{array}$ \\
\hline
\end{tabular}

\section{Data Analysis}

Initial Analysis: Re-Representation. Our initial analysis focused on the multiple representations used in the six lessons. Each representation is analyzed as a whole, with a long timescale and large compositional grain size. Lesson videos were viewed, coded, and tagged using Transana software. We first segmented the data by dividing the continuous sequence in a lesson video into meaningful discrete units. The average time of a segment is 4.5 minutes. We coded and tagged each segment according to four categories: teaching activities (e.g., teacher explanation or group experiment), participation structures (e.g., teacher monologue or class discussion), thematic content (e.g., bacteria buildup), and the representations used (e.g., group poster); see Table 1. At this level of analysis, verbal dialogue from the video data was analyzed at the grain size of an exchange (a string of utterances between participants for a specific purpose). The dialogue was not transcribed at this point due to the time-consuming nature of transcription.

The tags inserted into the video allowed us to track the use of a particular representation throughout the lesson unit and follow how it was transformed by the teacher or students. In other words, we tracked the sequences of re-representations. This analysis provided insight into to the social process of learning with representations, identified the sequence 
of re-representations involved, and allowed us to select focal representations for the next phase of analysis. This multiple representations analysis was consistent with our theoretical approach in designing the curriculum and yielded information on re-representation. However, we found it insufficient to fully explicate our observations. In particular, we wished to understand why different groups came up with varying interpretations of the same phenomena. We realized that we would need to delve deeper into how students interacted with a representation to make meaning. Only by examining the shorter timescale processes in a fine-grained manner could we understand the long timescale sequences of re-representation and learning across multiple lessons. This is what motivated us to use the analytical tools of multimodality.

Second-Phase Analysis: Semiotic Affordances. Our second-phase analysis followed a multimodal approach in focusing on a selected representation. With a short timescale and fine compositional grain size, we focused on the components of the analyzed representation. We selected two representations for further analysis based on our earlier analysis of the re-representation sequences. One representation was the result of the students' group discussions on the first lesson, and another was the product of their group presentations on the sixth and final lesson. These representations were selected first because of the multimodal richness of the corresponding episodes and second because the episodes on the first and final lesson could give a sense of the trajectory of the students' development of ideas over the lesson unit. In terms of the thematic content, the two representations dealt with "self-cleaning nanotech surfaces" (henceforth, self-cleaning). Surfaces that are smooth at the nanoscale harbor fewer bacteria and are used in commercial products including toilets (while electrostatics also influence the propensity of bacteria to cling to a surface, the curriculum only focused on surface roughness). Self-cleaning was being investigated in the context of the project-based unit on avoiding bacterial outbreaks at school.

For each of the selected representations, we transcribed the corresponding video segments and carried out a detailed multimodal discourse analysis. At this level of analysis, spoken language was analyzed at the level of a clause. Clauses function in English as the basic unit that semantically constructs a particular event or sense of experience (Halliday, 1978). Sentences may contain several clauses, joined together through conjunctions such as "because" or "and." We then interpreted the meaning of each clause through the semantic relationship among the words in the clause; for instance, the clause "the surface is bumpy" is an attributive relationship between a carrier and its attribute whereas "surface has bumps" is a possessive relationship between a carrier and its possessions. "You can feel the bumps" involves an agent_- "you"-_doing something to an object. (For a list of semantic relationships, see Lemke, 1990.)

For every verbal clause that we analyzed, we also examined the corresponding nonverbal actions and representations that the participants were oriented to in the video segment. Visual elements found in the representations were analyzed using Kress and van Leeuwen's (2006) visual framework. For instance, a common visual representation drawn by the students during the first lesson is called an analytical structure, which relates visual elements in terms of a part-whole structure between a carrier (the whole) and its possessive attributes (the parts). Nonverbal actions such as pointing gestures were used to determine the component(s) of a representation that a student was referring to, whereas iconic and metaphorical gestures often supplemented the verbal communication with further information (see McNeill, 2005 for the various types and functions of gestures). Examples of these analytical methods will be further illustrated in the analysis. 
Iterative Nature of the Analysis. The findings from the semiotic affordances analysis were used to better understand a particular representation within a sequence of rerepresentation, which also shed light on the sequence as a whole. Likewise, prior and subsequent representations in the sequence helped us understand the fine-grained way in which students constructed meaning from one particular representation.

\section{RESULTS}

\section{Initial Analysis: Re-Representation}

The first lesson was aimed at building an understanding of self-cleaning. Students explored and modeled the role of surface roughness in allowing bacteria to cling onto a surface. The first activity was an experiment that used different grades of sandpaper to model surfaces of varying degrees of smoothness and grains of salt to model bacteria. Students explored the different degree of difficulty in removing the salt from each grade of sandpaper, using a note pad as a scraper. Subsequently, students used multiple representations (e.g., diagram, table) to construct scientific explanations of self-cleaning based on their observations. Table 2 shows the representations and learning activities used in this lesson.

According to our framework, these representations are artifacts designed to teach a science concept. While meaningful for the designer, they are initially devoid of any meaning to others - they are just sandpaper, salt, and a collection of writings and drawings. Meaning is made through the use of multiple representations. Each representation forms a part of a sequence of re-representations, and any meaning made with one representation depends on prior meanings made with preceding representations across space and time.

At the beginning of the lesson, Mary, Luke, and Dave experimented with the salt and sandpaper model. They individually recorded their observations in the form of written texts and drawings in a table in their individual worksheets. Next, they collaborated to prepare a group poster, which was to be used in a subsequent oral presentation, to explain their findings (see Figure 3). The sequence of re-representation included a physical experience transformed to a textual description and drawing, and then to a group poster. Following Hubber et al. (2010), we next analyze how the dynamic transformations in the students' representations corresponded with the teaching and learning sequences.

Initially, when the group started working on the group poster, with Luke drawing and Mary and Dave helping, they drew only the top view of the sandpaper to represent what they saw from the top looking down at the sandpaper (the rectangular images directly below the text labeling the three grades of sandpaper). About 5 minutes later, Mary interrupted Luke

\section{TABLE 2}

\section{Representations Used in the Curricular Lesson}

\begin{tabular}{|c|c|c|}
\hline & Representation & Curricular Purpose \\
\hline a & $\begin{array}{l}\text { Sandpaper and grains of } \\
\text { salts }\end{array}$ & $\begin{array}{l}\text { To simulate different surface textures } \\
\text { and bacteria respectively }\end{array}$ \\
\hline $\mathrm{b}$ & Written table in a worksheet & $\begin{array}{l}\text { For individual students to record their } \\
\text { observations and explanations }\end{array}$ \\
\hline C & $\begin{array}{l}\text { Written text and a diagram } \\
\text { in a worksheet }\end{array}$ & $\begin{array}{l}\text { To describe to students the } \\
\text { experimental procedures }\end{array}$ \\
\hline$d$ & $\begin{array}{l}\text { Drawings on a shared } \\
\text { poster paper }\end{array}$ & $\begin{array}{l}\text { For group of students to present to } \\
\text { the class }\end{array}$ \\
\hline
\end{tabular}




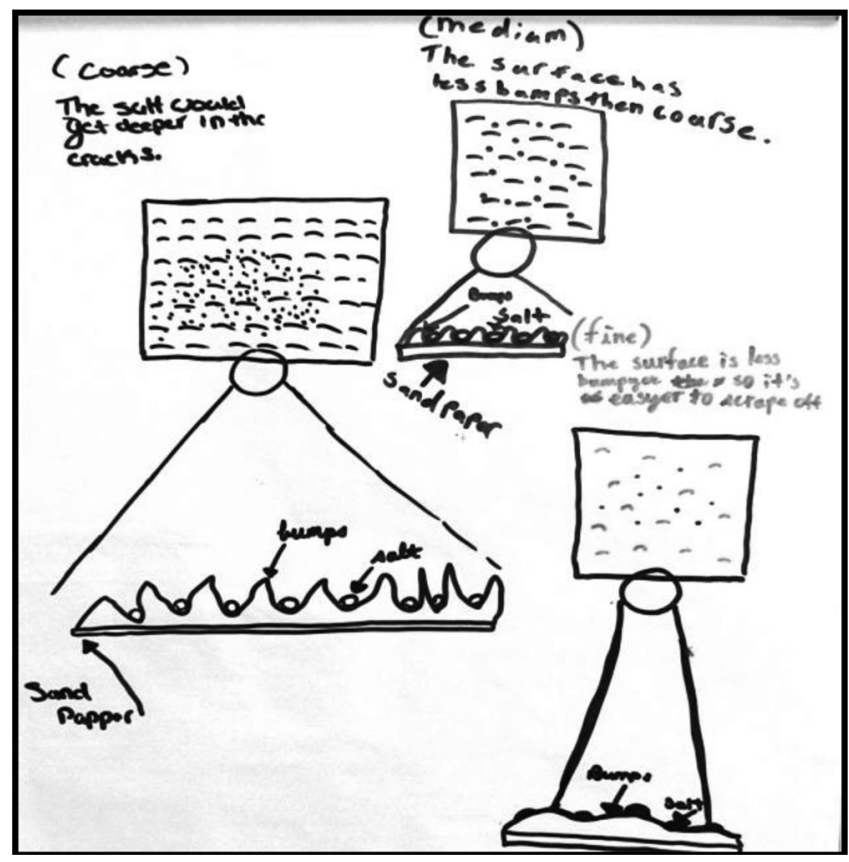

Figure 3. Text and drawings on group poster.

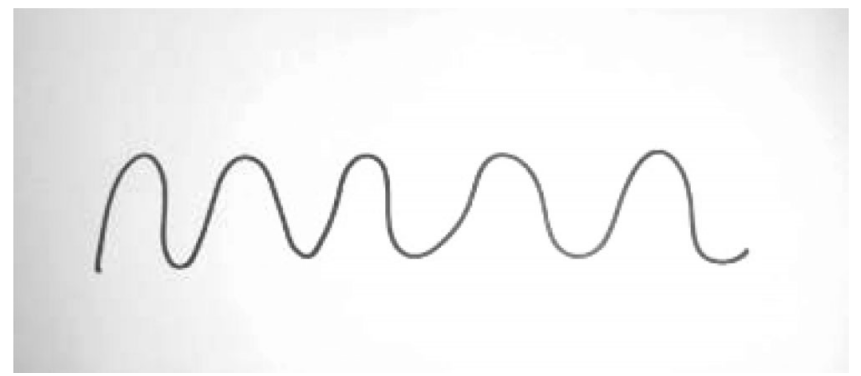

Figure 4. Drawing made by the teacher on the whiteboard.

and pointed out to her group an image made earlier by the lead teacher on the whiteboard (see Figure 4). The teacher made that image to explain the meaning of a side view before the class started working on the posters. Mary explained to the group that they needed to draw a side-view image of the sandpaper. She then turned to look at a diagram accompanying the written instruction on the worksheets (see Figure 5), took over the pen from Luke and proceeded to draw a "magnified" side-view image directly below the top-view drawing (labeled "sand paper" in Figure 3 at lower left).

Soon after Mary explained to the group what she was doing, Luke and Dave followed suit and each drew one side-view image extending from the top-view drawings on the group poster (Figure 3). About 3 minutes later, after the students had completed the poster, the researcher as the participant observer asked them to explain what they had drawn. Mary responded while looking and pointing at the top-view drawings on the poster: 


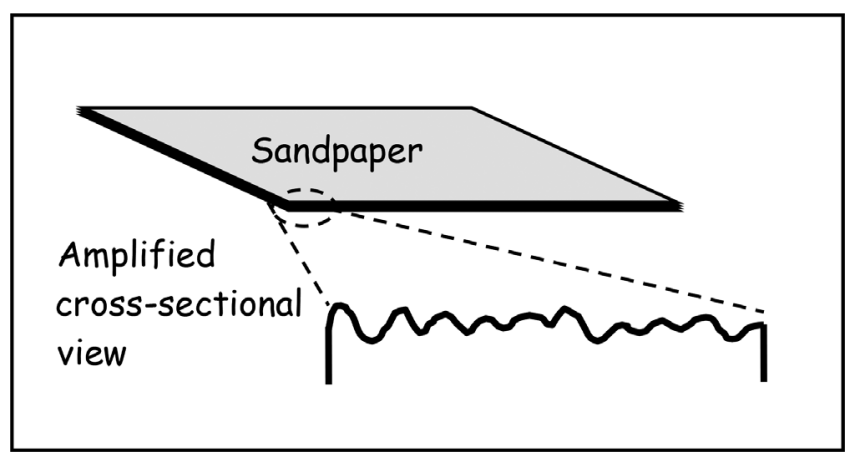

Figure 5. Diagram printed on a page of the student worksheets.

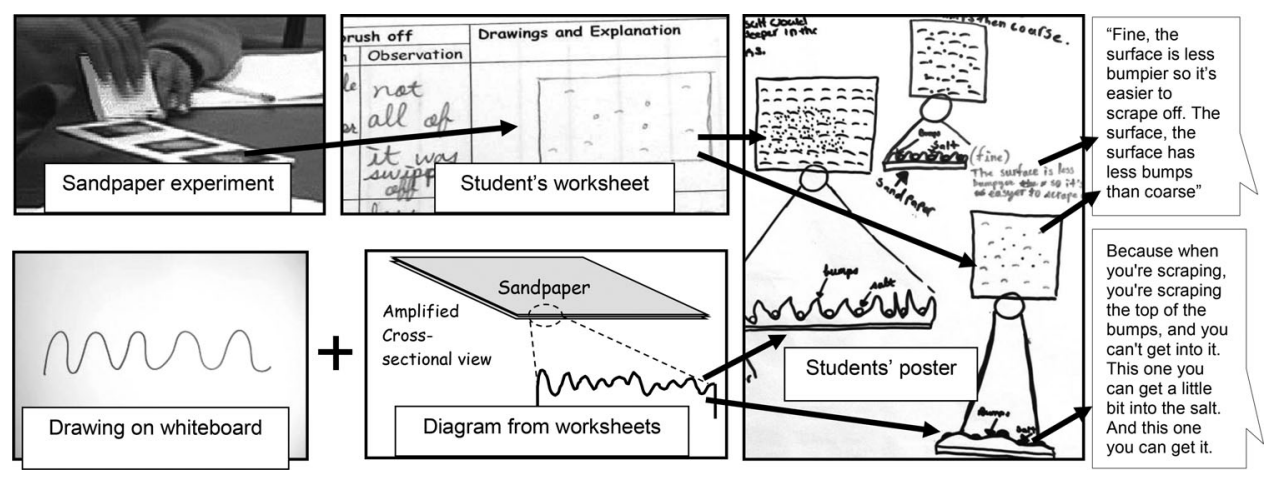

Figure 6. Sequences of re-representations leading to the students' group poster and their explanations of surface features. Top sequence shows the re-representation process from the sandpaper experiment to written text and top view drawings in each student's worksheet, and to top view drawings in the group poster. Bottom sequence shows how the teacher's drawing on the whiteboard, reproduced from the student worksheet (with accompanying text about it representing a magnified section of a side view), was re-represented to the side view drawings in the group poster, along with an elaboration of the magnified section of a side view (see text for explanation of the sequences).

Researcher: Ok, now that you have drawn all three, can you compare what you have drawn? And can you explain why this is the salt is easier to come out, for this. It is harder to come out?

Mary: For fine, the surface is less bumpier so it's easier to scrape off. The surface, the surface has less bumps than coarse.

Shortly after, the researcher pointed at the side-view drawings and posed the question again. Interestingly, the answer from Mary became very different. As she looked and pointed at the side-view drawings, she gave the following response:

Mary: Because when you're scraping, you're scraping the top of the bumps, and you can't get into it. This one you can get a little bit into the salt. And this one you can get it.

A summary of the sequences of re-representations leading to these two different responses is shown in Figure 6. As shown in the top sequence of Figure 6, the top views were re-represented from their drawings in the individual worksheets, which were themselves re-represented from the sandpaper experiment. In this sequence, the students' 
top-view representations reflected their experiences in brushing off the salt from the sandpaper in the prior experimental activity. This resulted in Mary's explanation that the fine-grade sandpaper is easier to scrape off because it "is less bumpier" and "has less bumps."

By contrast, as shown in the bottom sequence of Figure 6, the side-view drawings in the group poster were re-represented from the diagram on the students' worksheets and the lead teacher's drawing on the whiteboard. This resulted in Mary's explanation that "you can't get into" the salt, when it is on the coarse sandpaper.

The pattern of different explanations for side-view and top-view representations held for other groups as well. Consider two other examples from groups that only considered the top views of the sandpaper in their presentations:

Adrian: On the fine piece of um (points at top-view drawing), whatever it was, there wasn't much of any bump or anything, so the salt couldn't get hooked on much, so that's swept away easily.

Nigel: This one is easier because it has less bumps (points at fine-grain sandpaper). And this one is the hardest (points at coarse-grain sandpaper), because it has more bumps. And this one is in the middle.

Adrian's and Nigel's explanations were very similar to Mary's when she was also using a top-view drawing. All three explanations were based on the number of bumps as the central argument. On the other hand, groups that used a side-view drawing gave a different explanation. At the time when the lesson occurred, neither the students nor the teachers noted that the two explanations had very different meanings.

At this point, our analysis on multiple representations has identified two sequences of re-representation, which led to two different explanations. It has also led us to identify the group poster (i.e., Figure 3 ) as a representation that required further in-depth analysis. Although this initial analysis gave us an overview over a broad timescale, it was not able to tell us how the two sequences led to the production of different meanings by the students. According to our framework (see lower portion of Figure 1), a fine-grained analysis of the semiotic affordances of both the top- and side-view drawings is required to understand how the two different explanations for the phenomenon of self-cleaning were generated. This is the focus of the multimodal analysis in the next phase.

\section{Second-Phase Analysis: Semiotic Affordances}

In this section, we used a multimodal approach to analyze how Mary's group made meaning with the top-view drawing, followed by that with the side view. The grain size of analysis for spoken language is at the level of a clause. Thus, the transcript in the following excerpts is divided into individual clauses. For each clause, we include a description or screen capture of their nonverbal actions (e.g., gestures, direction of gaze) that were captured in our video data. The grain size of analysis for visual representations is at the level of components (e.g., a curve representing a bump or a dot representing a grain of salt).

The following excerpt shows the interaction between the researcher (R), Mary (M), and Luke (L) after they had completed the poster. As shown from the gesture and gaze column in the excerpt, Mary was oriented to the top-view drawings on the poster as she responded to the researcher. 
Excerpt 1: Analysis of meaning-making with the top-view drawing (22:56-23:45)

\begin{tabular}{|c|c|c|c|}
\hline & & Verbal Utterances & Gesture/Gaze \\
\hline $\begin{array}{l}1 \\
2\end{array}$ & $\mathrm{R}$ & $\begin{array}{l}\text { ok, now that you have drawn all three, } \\
\text { can you compare what you have drawn? }\end{array}$ & \\
\hline 3 & & $\begin{array}{l}\text { and can you explain why this is the salt } \\
\text { is easier to come out, }\end{array}$ & points to fine top-view \\
\hline 4 & & for this it is harder to come out? & points to coarse top-view \\
\hline 5 & M & oh, it's already. already said it & \\
\hline 6 & & for fine, the surface is less bumpier & $\begin{array}{l}\text { reads from text written above } \\
\text { fine top-view }\end{array}$ \\
\hline 7 & & so it's easier to scrape off & \\
\hline 8 & & $\begin{array}{l}\text { the surface. The surface has less } \\
\text { bumps than coarse }\end{array}$ & $\begin{array}{l}\text { reads from text written above } \\
\text { medium top-view }\end{array}$ \\
\hline 9 & $\mathrm{R}$ & $\begin{array}{l}\text { can you use your diagram to explain } \\
\text { this? I mean }\end{array}$ & \\
\hline 10 & M & it is there I guess & $\begin{array}{l}\text { points to text above fine } \\
\text { top-view }\end{array}$ \\
\hline 11 & $\mathrm{R}$ & $\begin{array}{l}\text { so can you use this to explain to me why } \\
\text { is it easier? }\end{array}$ & points to fine top-view \\
\hline 12 & M & oh, the surface is less bumpier & $\begin{array}{l}\text { points to text above fine } \\
\text { top-view }\end{array}$ \\
\hline 13 & & so it's easier to scrape off & \\
\hline 14 & & yet the salt has nowhere to hide & $\begin{array}{l}\text { points to a red dot inside fine } \\
\text { top-view }\end{array}$ \\
\hline
\end{tabular}

Using Halliday's (1994) linguistic analysis, we observed that there are two main semantic relationships in Mary's explanation. The first is an attributive relationship between an object (i.e., surface) and one of its attributes (bumpiness), as seen in "less bumpier" in (6) and (12). The second is a possessive relationship between a carrier (i.e., surface) and its possessions (i.e., bumps), as seen in "has less bumps" in (8). Next, using Kress and van Leeuwen's (2006) visual grammar, we analyzed the top-view drawings (see Figure 7). Each drawing realizes a possessive relationship between a carrier (rectangular boxes) and its possessions (curves and dots). In a linguistic sense, each drawing is saying that there are bumps and salt (represented by curves and dots) inside the sandpaper. Furthermore, we saw that the students drew progressively more curves and dots for the fine-, medium-,

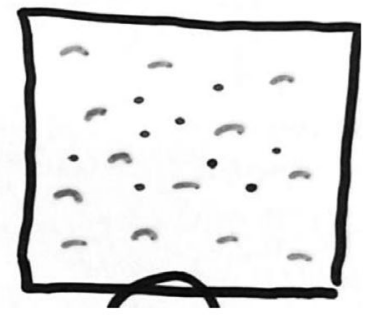

Fine

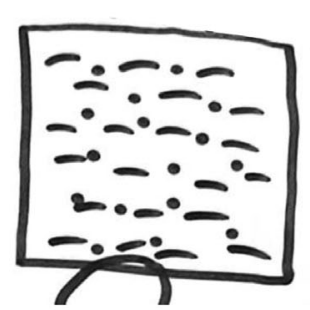

Medium

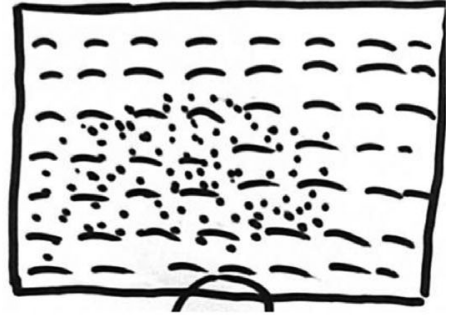

Coarse

Figure 7. Top-view images of sandpapers with bumps and salt. 
and coarse-grain sandpaper. Both the linguistic and visual analyses indicate the possessive relationship.

Complementing the visual analysis with the linguistic analysis, we can infer that the word "bump" means a protruding peak that the students must have imagined the sandpaper to have, based on and re-represented from their sensory experiences with the sandpaper. We also infer that students understand "bumpiness" as a quality that arises from the number of protruding peaks. Students' reasoning when using the top-view representation is that the number of peaks (bumps) determines the ease with which the bacteria can be scraped off a surface. We call this the argument of quantity.

In the next analysis, we analyze and compare how the students' argument changed as they used the side-view drawing. The following excerpt occurred shortly after Excerpt 1 . A crucial turn of events here was that the researcher started pointing at the side-view drawings on the poster (18-20). Consequently, Mary (M), Luke (L), and Dave (D) were oriented to the side-view drawings on the poster as they responded to the researcher $(\mathrm{R})$.

Excerpt 2: Analysis of meaning-making with the side-view drawing (24:18-25:05)

\begin{tabular}{|c|c|c|c|c|}
\hline & & Verbal Utterances & Gesture/Gaze & Video Snapshots \\
\hline 18 & $\mathrm{R}$ & $\begin{array}{l}\text { So what's the } \\
\text { difference between } \\
\text { this bump }\end{array}$ & $\begin{array}{l}\text { points to medium side } \\
\text { view }\end{array}$ & \\
\hline 19 & & this bump & $\begin{array}{l}\text { points to coarse side } \\
\text { view }\end{array}$ & \\
\hline 20 & & and this bump? & points to fine side view & \\
\hline 21 & $M$ & $\begin{array}{l}\text { this one you can get } \\
\text { into }\end{array}$ & points to fine side view & \\
\hline 22 & & $\begin{array}{l}\text { this one you can't get } \\
\text { into }\end{array}$ & $\begin{array}{l}\text { points to coarse side } \\
\text { view }\end{array}$ & \\
\hline 23 & & and this [one & $\begin{array}{l}\text { points to medium side } \\
\text { view }\end{array}$ & \\
\hline 24 & $\mathrm{~L}$ & [you could & & \\
\hline 25 & $\mathrm{D}$ & [you sort of can & & \\
\hline 26 & $\mathrm{R}$ & $\begin{array}{l}\text { but you say you can't } \\
\text { get into, cannot get } \\
\text { into what? }\end{array}$ & & \\
\hline 27 & M & get into [the salt] & $\begin{array}{l}\text { points to medium side } \\
\text { view }\end{array}$ & \\
\hline 28 & $\mathrm{~L}$ & [the salt gets more & $\begin{array}{l}\text { hand gestures } \\
\text { downwards over } \\
\text { medium side view }\end{array}$ & \\
\hline 29 & M & gets to [the salt and & & \\
\hline 30 & $\mathrm{~L}$ & $\begin{array}{l}\text { you can get into the } \\
\text { salt. the salt can } \\
\text { gets into the } \\
\text { sandpaper }\end{array}$ & & \\
\hline 31 & & $\begin{array}{l}\text { but it can get into this } \\
\text { one }\end{array}$ & $\begin{array}{l}\text { fingers land on coarse } \\
\text { side view }\end{array}$ & \\
\hline 32 & $\mathrm{R}$ & $\begin{array}{l}\text { But if you say the salt } \\
\text { cannot get in, but } \\
\text { this is a salt right? }\end{array}$ & $\begin{array}{l}\text { points to a circle in } \\
\text { coarse side view }\end{array}$ & \\
\hline
\end{tabular}




\section{Excerpt 2: Continued}

\begin{tabular}{|c|c|c|c|c|}
\hline & & Verbal Utterances & Gesture/Gaze & Video Snapshots \\
\hline 33 & & It's inside & & \\
\hline 34 & $M$ & $\begin{array}{l}\text { yah. because when } \\
\text { you're scraping, }\end{array}$ & $\begin{array}{l}\text { points to peaks of } \\
\text { coarse side view }\end{array}$ & \\
\hline 35 & & $\begin{array}{l}\text { you're scraping the top } \\
\text { of the bumps }\end{array}$ & & \\
\hline 36 & & $\begin{array}{l}\text { and you can't get into } \\
\text { it }\end{array}$ & $\begin{array}{l}\text { gestures scraping } \\
\text { motion }\end{array}$ & \\
\hline 37 & & $\begin{array}{l}\text { this one you can get a } \\
\text { little bit into the salt }\end{array}$ & $\begin{array}{l}\text { points to a groove in } \\
\text { medium side view }\end{array}$ & \\
\hline 38 & & $\begin{array}{l}\text { And this one [you can } \\
\text { get it] }\end{array}$ & $\begin{array}{l}\text { points to a groove in } \\
\text { fine side view }\end{array}$ & \\
\hline 39 & L & $\begin{array}{l}\text { [this] is the sandpaper } \\
\text { right here }\end{array}$ & $\begin{array}{l}\text { traces the length of } \\
\text { coarse side view }\end{array}$ & \\
\hline 40 & & $\begin{array}{l}\text { it's trying to get down } \\
\text { here }\end{array}$ & $\begin{array}{l}\text { traces downward } \\
\text { motion into a } \\
\text { groove of coarse } \\
\text { side view }\end{array}$ & \\
\hline 41 & & $\begin{array}{l}\text { So basically it's not all } \\
\text { the way down }\end{array}$ & & \\
\hline 42 & $M$ & you can't get it at all & & \\
\hline
\end{tabular}

[] indicates start and end points of overlapping speech.

Again, we began with a linguistic analysis of the key clauses. Unlike the first excerpt, there was a notable shift in the grammatical subjects in clauses (21-22), (30-31), (36-38), and (42). Instead of "surface" (e.g., surface has less ...), the main grammatical subjects in the second excerpt are "you" or "it," which refers to the scraper (e.g., you can/can't get into). This corresponds to a shift from the earlier possessive relationship of the sandpaper (e.g., surface has bumps) to a different kind of semantic meaning. This meaning focuses on the transitive action (Halliday, 1994) of the scraper doing something to the salt/sandpaper (e.g., you can get into it). 


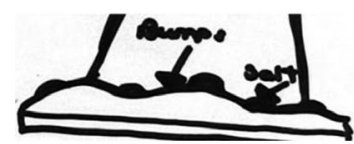

Fine

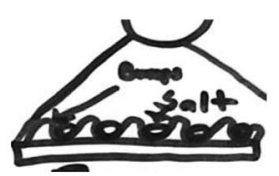

Medium

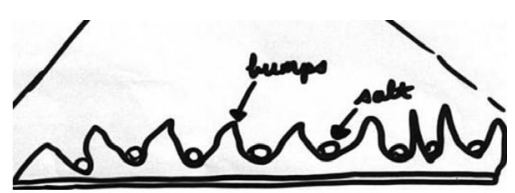

Coarse

Figure 8. Side-view images of sandpapers (carrier) with bumps (possessive attributes).

A visual analysis shows that the side-view drawings (see Figure 8) retain the possessive relationship between a surface carrier and its possessions, as in the first excerpt. Thus, one of the key differences in the students' explanation in this excerpt is that each of the modalities plays a different and complementary role: The verbal modality realizes the action of the scraper while the visual realizes the surface's possessive attributes of grooves of varying depths. As for the gestural modality, there are also some differences compared to the first excerpt. First, the students were pointing (deictic gestures) more specifically at a smaller part of the sandpaper drawings (see clauses 35, 37, and 38). Second, the students used some kind of actions to animate by resemblance (iconic gestures) the physical movement of the scraper in removing the salt (see clauses 36 and 41). On the other hand, few gestures were used in the first excerpt.

Collectively, the gestural, verbal, and visual modalities resulted in a different meaning. From the repeated and synchronized uttering of the phrases "get into," "get it," or "get down," with the deictic and iconic gestures (see 35-41) referencing the side-view drawings, we can infer that the students' argument centers on the varying depth of the sandpaper "bumps." We call this the argument of depth. From the point of view of the curriculum, this argument is a more accurate form of reasoning for the concept of self-cleaning as compared to the earlier argument of quantity. In fact, the fine sandpaper has many more bumps than the medium or coarse sandpaper, so the argument of quantity that states that the fine sandpaper "has fewer bumps" misrepresents the phenomenon being modeled.

While the large grain-sized re-representation analysis showed that the two different representations led to different explanations, this fine-grained semiotic affordances analysis revealed how the representations supported the different explanations. Although both the top- and side-views realize a similar possessive relationship of a carrier (sandpaper surface) and its possessions (bumps), there is one crucial difference between the two representations. The top view is what Kress and van Leeuwen (1996) call an inclusive analytical structure, which shows only some of the possessive attributes as bumps and the rest of the surface of the carrier as blank space. On the other hand, the side view is an exclusive analytical structure that shows the entire surface of the carrier covered by the possessive attributes. Critically, in a side-view representation one cannot draw bumps without also drawing grooves on the surface. By contrast, in a top-view representation, bumps can be drawn without the grooves on the surface. By choosing to represent through a side view, both the protruding bumps and depressed grooves will be included in the representation. Therefore, although both the top- and side-view representations may appear to refer to the same phenomenon, each has different semiotic affordances that allow and constrain different kinds of meanings and argument that can be made in conjunction with the contextualizing utterances and gestures.

While research on multiple representations recognizes that different representations may constrain, complement, or help construct meaning (Ainsworth, 2006), the analysis that we presented here develops and explains how this meaning-making process occurs. Our analysis reveals how the processes at a shorter timescale (e.g., dialogue and gestures around the side-view representation) build up to the processes at a longer timescale (creation of 
the group poster and subsequent presentation of the group's ideas). We thus show how the fine-grain, short timescale analysis based on the multimodal representations literature can inform the large-grain, long timescale analysis based on the multiple representations literature. Analyzing the inclusive/exclusive analytical structure of these representationsfrom a multimodal perspective-helps explain how the side-view representation captures important features of the phenomenon that the top-view drawing does not, thus greatly enriching the understanding of the sequence of re-representation. On the other hand, a finegrained multimodal analysis of the group poster alone would miss important contextual information from the large-grained re-representation analysis. For instance, the physical experiment explains why the students talked about "bumps," the individual sketches explain why the group poster initially included the top-view representations, and the diagram drawn by the teacher on the whiteboard explains why the students later drew a side view. It is precisely these connections across temporal and compositional dimensions that our integrative framework allows.

\section{Analysis on the Sixth Lesson}

In this section, we move ahead to the last day of the lesson unit to show another example of our analysis. As the analytical process is very similar to what has been illustrated earlier, we will provide only the main results from our analysis.

On the sixth and final day of the lesson unit, each group of students was working to prepare a 3-minute skit to advertise the product of a nanotoilet-a recent commercial application of self-cleaning in a bathroom accessory. During the brainstorming phase, which occurred on the fifth lesson, students decided within their groups what representations they would use in their skit. Mary's group decided to create a poster. From the analysis on the multiple representations used, the sequence of re-representations over the 2 days was a commercial advertisement of a toilet that used a supersmooth nanotech finish, a written rubric, a group poster, and a video of their skit. As shown in Figure 9, their poster included side views comparing a conventional toilet to the smoother nanotoilet. They did not use the top-view representations. This shows that they recognized the top view was not useful for their explanations.

We selected the group poster and its corresponding video segment for a fine-grained multimodal analysis so that a comparison could be made with the earlier multimodal analysis of the poster from the first lesson. The linguistic analysis of the students' explanation

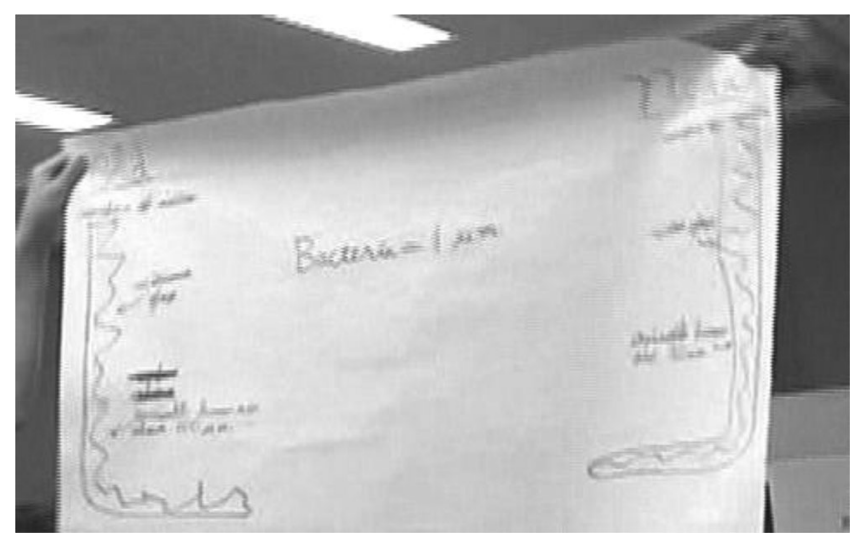

Figure 9. Group poster created by Mary's group. 
(which was collaboratively made by Mary and Luke) revealed two semantic relationships that were also made during the first lesson (see Excerpt 2). As seen from the following utterances, one was the possessive relationship of a carrier and its possessive attributes ("toilet has invisible bumps"), and the other a transitivity action of the agent removing the residual bacteria ("water flows," "bacteria to come straight off"):

Mary: The new toilet has invisible bumps too, but they are thirty nanometers, and nanometer is thousand times smaller than a micrometer. So a bacterium won't fit in that bump that small.

Luke: It would be smoother for the bacteria to come straight off when the water flows when you flush the toilet. (emphasis added)

Again, the verbal, visual, and gestural semiotic modalities play different and complementary roles in the overall construction of their explanation, which reiterated their argument of depth from the first lesson. The group also incorporated several additional concepts they had picked up during intervening lessons. One important concept that the students learned on the third lesson was the mathematical relationship between a millimeter, micrometer, and nanometer; other information was the size of a bacterium (see Figure 9) and of the surface features of the nanotech toilet (e.g., "invisible bumps"; see excerpt above). Mary was then able to provide convincing evidence for her assertion that a bacterium "won't fit" into the surface features of the new nanotoilet. Through this mathematical reasoning, she was able to construct what we call the argument of relative size.

\section{DISCUSSION}

Comparing the analyses of the two phases with different timescale and grain size, we found that each analysis plays a mutually complementary role in illuminating students' learning with representations. In the analysis of multiple representations with a long timescale and large grain size, we learned how the different sequences of re-representations led to the production of two different representations of surface features (top vs. side view). We showed that several groups produced two different explanations depending on the representation they focused on. We also showed how the re-representation process incorporated the interaction and context of preceding activities and projected them into subsequent activities. However, this analysis did not shed light on how the students made meaning with the representations, nor why the explanations differed. In the fine-grained analysis of multimodal representations, we learned how the students used the top- and side-view drawings, along with their utterances and gestures, to construct different meanings. Although both representations portray bacteria being trapped within the cracks or pits of different surfaces, their semiotic affordances are different and supported different explanations. Thus, to understand how meanings emerged through the situated use of representations, a fine-grained analysis of the composite parts of a representation and how they were integrated multimodally by the learners was undertaken. At the same time, if the analysis was carried out only on a single representation, we would miss important details in the overall understanding of the learning process in this lesson unit. Thus, the multiple representations analysis complements the fine-grained analysis by providing this contextual information. The complementary roles between multiple and multimodal representations is summarized in Figure 10.

We propose that our integrative framework is a step toward the goal of a unified multirepresentational framework envisioned by Yore and Treagust (2006). We have shown how our framework integrates the research on multiple representations (archetypically in 


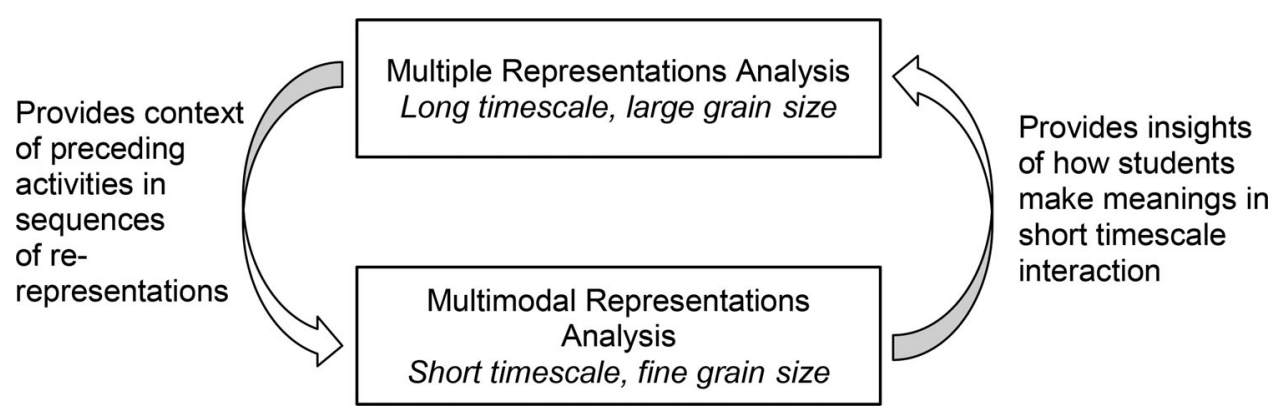

Figure 10. Complementary relationship between multiple and multimodal representations analysis.

the top left quadrant of Figure 1) and research on multimodal representations (archetypically in bottom right quadrant of Figure 1). We next show how our integrative framework suggests promising new directions for the analysis of studies that fall into the other two quadrants of Figure 1. For instance, we note that many of the studies with large grain size but short timescale (upper right quadrant) are multiple representation analyses that focus on the relative effectiveness of single representations rather than longer instructional episodes employing many representations. These studies can benefit from a multimodal analysis to begin determining why a given configuration or type of representation is more effective than another. For instance, the contiguity principle states that narration in words and images should be simultaneous rather than sequential so that it is easier for a learner to build connections in his/her working memory (Mayer, 2001). A fine-grained multimodal analysis can elaborate the processes by which those connections are made, as we showed above for the case of self-cleaning surfaces. Studies with small grain size but longer timescales (bottom left quadrant) are multimodal analyses focusing on multiple teaching/learning episodes across time. Such studies can add a layer of analysis that examines the sequential re-representation process; analyzing how students transform one representation into another in situated social activities, in addition to analyzing how the composite elements within and across representations interact to support the meaning-making process.

\section{CONCLUSION AND IMPLICATIONS}

Our integrative framework can inform future research on science learning with and through representations. From Vygotsky's (1986) sociocognitive theory, researchers have come to broadly understand representations as symbolic tools that mediate social learning and human cognition (e.g., Bransford, 2000; Kozma, Chin, Russell, \& Marx, 2000). However, the mechanism by which this occurs is still not well understood. Our framework suggests the importance of considering re-representation as well as semiotic affordances in the analysis of students' learning with representations. This implication for research has a parallel implication for practice: For students to develop better scientific understanding, they must engage more actively in the construction of representations (Hubber et al., 2010; Waldrip, Prain, \& Carolan, 2010), as they did in the summer program we studied.

In this paper, we have shown how our integrative framework can be used retrospectively to analyze student representation practices and artifacts. Future work is needed to explore how our framework can be used prospectively in the design of curriculum and instruction. Our inclusion of side-view and top-view representations in the curriculum materials was based on general multiple representations principles, and the research value of a fine-grained 
examination of the multimodal representations emerged rather than being purposefully designed into the materials. Having observed that some groups did not generate the argument of depth and relative size as a result of not using a side-view way of representing, we consequently realized the importance of building in opportunities for students to engage more deeply with the multimodal components of representations. We expect that our framework and supporting case study will provide guidance in developing future materials that can better support student learning, in addition to future research leading to the iterative refinement of this unified multirepresentational framework.

We wish to express our gratitude to the students, teachers, and administrators of the school district who collaborated in this study. We also acknowledge and thank Jay Lemke, Joseph Krajcik, Chris Quintana, and Leema Berland for their comments and suggestions on the analyses presented in this paper. Any opinions expressed in this work are those of the authors and do not necessarily represent those of the funding agencies.

\section{REFERENCES}

Ainsworth, S. (2006). DeFT: A conceptual framework for considering learning with multiple representations. Learning and Instruction, 16(3), 183-198.

Ainsworth, S., Bibby, P., \& Wood, D. (2002). Examining the effects of different multiple representational systems in learning primary mathematics. Journal of the Learning Sciences, 11(1), $25-61$.

Airey, J., \& Linder, C. (2009). A disciplinary discourse perspective on university science learning: Achieving fluency in a critical constellation of modes. Journal of Research in Science Teaching, 46, 27-49

Baldry, A., \& Thibault, P. J. (2006). Multimodal transcription and text analysis. London: Equinox.

Bransford, J. D. (2000). How people learn: Brain, mind, experience, and school. Washington, DC: National Academy Press.

Chandler, P., \& Sweller, J. (1996), Cognitive load while learning to use a computer program. Applied Cognitive Psychology, 10, 151-17.

Fredlund, T., Airey, J., \& Linder, C. (2012). Exploring the role of physics representations: An illustrative example from students sharing knowledge about refraction. European Journal of Physics, 33, 657-666.

Gilbert, J. K., \& Treagust, D. F. (Eds.). (2009). Multiple representations in chemical education. Dordrecht, The Netherlands: Springer.

Halliday, M. A. K. (1978). Language as social semiotic: The social interpretation of language and meaning. London: Edward Arnold.

Halliday, M. A. K. (1994). An introduction to functional grammar. London: Arnold.

Hand, B., Alvermann, D. E., Gee, J., Guzzetti, B. J., Norris, S. P., Phillips, L. M., et al. (2003). Message from the "Island group": What is literacy in science literacy? Journal of Research in Science Teaching, 40, 607-615.

Hand, B., Gunel, M., \& Ulu, C. (2009). Sequencing embedded multimodal representations in a writing to learn approach to the teaching of electricity. Journal of Research in Science Teaching, 46(3), 225-247.

Hubber, P., Tytler, R., \& Haslam, F. (2010). Teaching and learning about force with a representational focus: Pedagogy and teacher change. Research in Science Education, 40, 5-28.

Jaipal, K. (2009). Meaning making through multiple modalities in a biology classroom: A multimodal semiotics discourse analysis. Science Education, 94, 48-72.

Kozma, R. (2003). The material features of multiple representations and their cognitive and social affordances for science understanding. Learning and Instruction, 13, 205-226

Kozma, R., Chin, E., Russell, J., \& Marx, N. (2000). The roles of representations and tools in the chemistry laboratory and their implications for chemistry learning. Journal of the Learning Sciences, 9(2), 105-143.

Krajcik, J., \& Blumenfeld, P. C. (2006). Project-based learning. In R. K. Sawyer (Ed.), The Cambridge handbook of the learning sciences (pp. 317-334). New York: Cambridge University Press.

Kress, G., Jewitt, C., Ogborn, J., \& Tsatsarelis, C. (2001). Multimodal teaching and learning: The rhetorics of the science classroom. London: Continuum.

Kress, G., \& van Leeuwen, T. (2006). Reading images: The grammar of visual design (2nd ed.). London: Routledge.

Lemke, J. L. (1990). Talking science: Language, learning and values. Norwood, NJ: Ablex.

Lemke, J. L. (1998). Multiplying meaning: Visual and verbal semiotics in scientific text. In J. Martin \& R. Veel (Eds.), Reading science (pp. 87-113). London: Routledge. 
Lemke, J. L. (2000). Across the scales of time: Artifacts, activities, and meanings in ecosocial systems. Mind, Culture and Activity, 7(4), 273-290.

Márquez, C., Izquierdo, M., \& Espinet, M. (2006). Multimodal science teachers' discourse in modeling the water cycle. Science Education, 90, 202-226.

Mayer, R. E. (2001). Multimedia learning. Cambridge, England: Cambridge University Press.

McNeill, D. (2005). Gesture and thought. London: University of Chicago Press.

Pozzer-Ardenghi, L., \& Roth, W. M. (2007). On performing concepts during science lectures. Science Education, 91, 96- 114.

Prain, V., Tytler, R., \& Peterson, S. (2009). Multiple representation in learning about evaporation. International Journal of Science Education, 31(6), 787-808.

Prain, V., \& Waldrip, B. (2006). An exploratory study of teachers' and students' use of multi-modal representations of concepts in primary science. International Journal of Science Education, 28, 1843-1866.

Rosengrant, D., Etkina, E., \& Van Heuvelen, A. (2007). An overview of recent research on multiple representations. AIP Conference Proceedings, 883(1), 149-152.

Roth, W.-M., \& Tobin, K. (1997). Cascades of inscriptions and the re-presentation of nature: How numbers, tables, graphs, and money come to re-present a rolling ball. International Journal of Science Education, 19(9), $1075-1091$.

Schnotz, W., \& Bannert, M. (2003). Construction and interference in learning from multiple representation. Learning and Instruction, 13, 141-156.

Tang, K.-S., \& Moje, E. (2010). Relating multimodal representations to the literacies of science. Research in Science Education, 40, $81-85$.

Tang, K.-S., Tan, S. C., \& Yeo, J. (2011). Students' multimodal construction of work-energy concepts. International Journal of Science Education, 33, 1775-1804.

Vygotsky, L. (1986). Thought and language. Cambridge, MA: MIT Press.

Waldrip, B., Prain, V., \& Carolan, J. (2010). Using multi-modal representations to improve learning in junior secondary science. Research in Science Education, 40, 65-80.

Yore, L. D. \& Hand, B. (2010). Epilogue: Plotting a research agenda for multiple representations, multiple modality, and multimodal representational competency. Research in Science Education, 40, 93-101.

Yore, L. D., \& Treagust, D. F. (2006). Current realities and future possibilities: Language and science literacyempowering research and informing instruction. International Journal of Science Education, 28, 291-314. 